Research Paper

\title{
Economic Analysis in a Diagnosis Related Groups System for Two-stage Exchange of Prosthetic-joint Infections
}

\author{
Arnaud Fischbacher ${ }^{\bowtie}$, Karine Peltier, Olivier Borens \\ Centre hospitalier universitaire vaudois (CHUV), Service d'orthopédie et de traumatologie, Rue du Bugnon 46, 1011 Lausanne, Switzerland. \\ $\triangle$ Corresponding author: Arnaud.fischbacher@unil.ch \\ (C) Ivyspring International Publisher. This is an open access article distributed under the terms of the Creative Commons Attribution (CC BY-NC) license \\ (https://creativecommons.org/licenses/by-nc/4.0/). See http://ivyspring.com/terms for full terms and conditions.
}

Received: 2018.03.18; Accepted: 2018.09.12; Published: 2018.11.24

\begin{abstract}
Background: There is a constant increase of joint arthroplasties performed, with an infectious risk of $1-2 \%$. Different therapeutic options for prosthetic-joint infections exist, but surgery remains essential. With a two-stage exchange procedure, a success rate above $90 \%$ can be expected. Currently, there is no consensus regarding the optimal interval duration between explantation and reimplantation. This retrospective study aimed to assess the economic impact of a two-stage exchange from a single-hospital perspective.

Methods: 21 patients who have undergone a two-stage exchange of a hip or knee prosthetic-joint infection at the University Hospital of Lausanne (Switzerland) from 2012 to 2013 were included. The revenues earned according to the Swiss Diagnosis Related Groups (SwissDRG) system introduced in 2012 and the costs were compared for each hospital stay.

Results: The remuneration ranged from 26'806 to 42'978 Swiss francs (CHF) ( 22'905-36'723 EUR, median 36'338 CHF, 31'049 EUR). The median total cost per patient was 76'000 CHF ( 65'000 EUR) (51'151 to 118'263; hip median 79'744, knee median 66'708). The main determinant of the costs was the length of the hospital stay. Revenues never covered all the costs, even with a short-interval procedure. The hospital lost a median of 35'000 CHF per patient ( 30'000 EUR) (22'280 to 64'666).

Conclusion: The current DRG system may not be specific enough for rewarding prosthetic-joint infections. Several options could be considered to act on the length of the hospital stay. In order to cover costs in complicated cases, such as prosthetic-joint infections, more specific DRGs are needed.
\end{abstract}

Key words: prosthetic-joint infection, two-stage exchange, economic analysis

\section{Introduction}

In Switzerland, more than $35^{\prime} 000$ joint arthroplasty procedures are performed every year to improve the quality of life of an aging population.[1] Prosthetic-joint infections (PJI) are rare, with an incidence of $1-2 \%$, but they represent serious complications in terms of morbidity and costs.[2] For adequate care of a patient, the surgeon has to choose between different therapeutic options, of which surgery remains essential. If a replacement of the infected joint arthroplasty is needed, a success rate above $90 \%$ can be expected with a two-stage procedure.[2] Two-stage revision includes removal of all foreign material, debridement, and reimplantation of a new prosthesis after a variable period of time to manage the infection. Intravenous antimicrobial treatment is administered followed by oral therapy 
for a total of three months. Currently, there is no consensus regarding the optimal interval duration between the prosthesis explantation and reimplantation procedure. The interval varies from two weeks to several months [Figure 1].[2,3]

The economic consequences associated with treating periprosthetic infections are known. Already in 1990, Sculco et al. demonstrated that the inadequate reimbursement of the treatment of prosthetic-joint infections causes an economic burden to the hospital and consequently to the healthcare system.[4,5] In addition, between 1990 and 2004, a nearly two-fold increase in the incidence of these infections was observed in the United States.[6] The annual cost of infected revisions for US hospitals is projected to exceed 1.6 billion dollars by 2020.[7]

The Swiss Diagnosis Related Groups (SwissDRG; SDRG) tariff system for acute somatic inpatient hospital services was introduced in January 2012.[8] It consistently sets the remuneration of hospital services according to the latest revision of the Swiss Health Insurance law (LAMal) voted in 2007. The DRG system was invented as a patient classification system in 1967 by the scientists Robert Barclay Fetter and John Devereaux Thompson at the University of Yale. It was first implemented in 1983 in the USA to measure each individual patient's consumption of hospital resources. $[5,9,10]$ Since then, DRGs have been introduced in many countries. SwissDRG is supposed to provide homogenous, transparent and comparable hospital remuneration, improve efficiency and reduce costs.[10] In it, each hospital stay is assigned to a group of pathologies, at the end of hospitalization, and reimbursed by the insurance companies at a fixed rate.[11] This form of remuneration compensates hospitals for cases, taken as a whole. Therefore, hospitals are not paid for each therapeutic act.[12] The groups include admissions for similar diagnoses with treatments costs supposed to be comparable. A software with a classification algorithm (grouper) allocates an inpatient admission in a SDRG. This allocation applies to several criteria, including the condition that has requested most of the resources (principal diagnosis) which does not always match the hospitalization pattern [Figure 2].[8] Today 974 SDRGs are defined.

The literature contains few economic evaluations of the revenues from the treatment of prosthetic-joint infections.[5,13] This retrospective study intended to assess the economic impact of a two-stage exchange from a single-hospital perspective. We compared the revenues and the costs of each cases at the University Hospital of Lausanne in Switzerland from 2012, the year when the DRG system was introduced in Switzerland, to 2013.

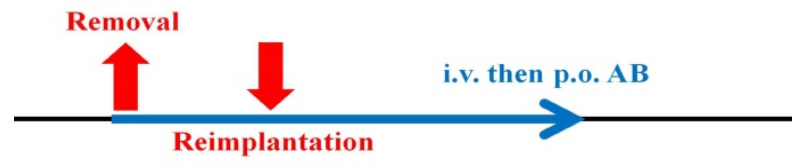

Figure 1. Two-stage exchange. (Adapted from [1])

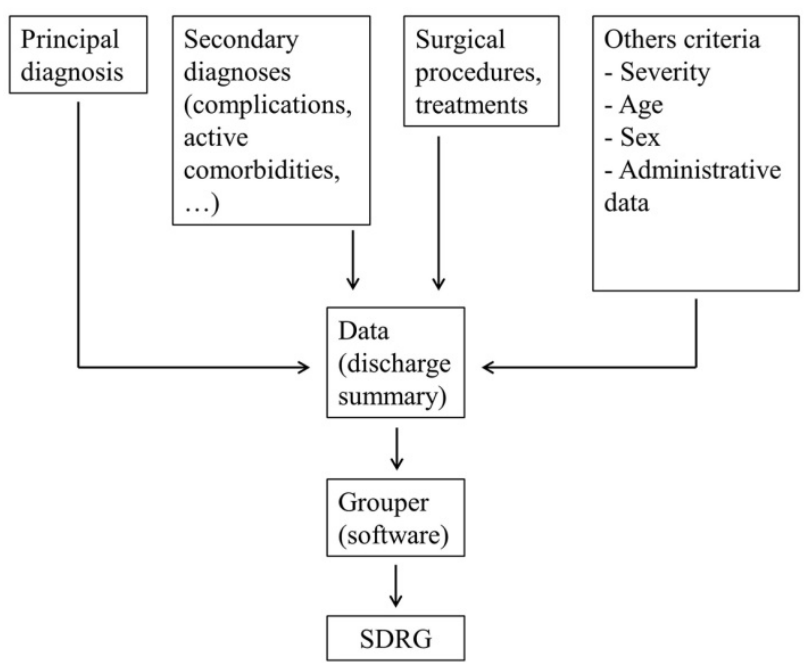

Figure 2. SDRG classification algorithm. (Adapted from [8])

\section{Methods}

\section{Patients}

The inclusion criteria were to have a two-stage exchange from January 2012 to December 2013, with a single stay at the University Hospital of Lausanne (CHUV) and a SDRG expected for a prosthetic-joint infection [Table 1]. Patients with multiple stays (e.g. temporary transfer to a peripheral hospital) were excluded for sake of consistent comparison [Figure 3]. Patients with another SDRG (e.g. post-operative transplant) were excluded as well. Data for the included patients was extracted from electronic files and retrospectively analyzed using standard software (Microsoft Excel, IBM SPSS).

\section{Revenues}

All economic data were obtained in Swiss francs (CHF) and converted to Euros (EUR), with an exchange rate of $1 \mathrm{CHF}$ equivalent to 0.8545 EUR. The revenue is the remuneration obtained by the hospital for each hospital stay. Each SDRG has a number of points (cost-weight), according to the gravity of the group's pathologies [Table 1]. The cost-weights are calculated measuring the cost for treatment of each SDRG in a sample of hospitals. They are adjusted annually. The base rate corresponds to the price of a SDRG point and is negotiated every year between each hospital and its insurance companies. The base rate was 10'400 CHF ( 8'886 EUR) in 2012 and 2013. 
The remuneration is obtained by multiplying the number of points (cost-weight) by the current price of the point (base rate) [Figure 4].[8]

For each SDRG, a "normal" length of hospital stay is defined. The cases in which the length of stay lays between the limits are qualified inliers. To minimize the economic incentive to refer a patient too soon, lengths of stays below the lower limit, called low-outliers, obtain a reduced remuneration. Conversely, remuneration of high-outliers, with a duration above the upper limit, is increased. Adjustments are done by increasing or decreasing the number of points (cost-weight) per day above or below the limits.

Table 1. SDRGs for prosthetic joint infections.

\begin{tabular}{lll}
\hline SDRG & Cost-weight & Definition \\
\hline I03A & $2012: 4.264$ & $\begin{array}{l}\text { Revision or replacement of the articulation of the } \\
\text { hip with the diagnosis of complication or } \\
\text { arthrodesis or age }<16 \text { years or bilateral } \\
\text { interventions or multiple important interventions } \\
\text { on the articulations of the legs with complex } \\
\text { intervention, with extremely severe complications } \\
\text { or malignant neoplasm }\end{array}$ \\
$\begin{array}{lll}\text { I03B } 2012: 2.543 & \begin{array}{l}\text { Revision or replacement of the articulation of the } \\
\text { hip with the diagnosis of complication or } \\
\text { arthrodesis or age }<16 \text { years or bilateral } \\
\text { interventions or multiple important interventions } \\
\text { on the articulation of the legs with complex } \\
\text { intervention, without extremely severe } \\
\text { complications or malignant neoplasm } \\
\text { Revision or replacement of the articulation of the } \\
\text { knee with the diagnosis of complication or } \\
\text { I04Z } 2012: 2.776\end{array} \\
\text { arthrodesis }\end{array}$ \\
\hline
\end{tabular}

\section{Costs}

The cost is the expense of the hospital for a hospital stay. We calculated the costs using a swiss standard approach named REKOLE (revision of cost accounting and charge capture).[14] It consists of a "top-down" cost-analysis where all the costs are attributed to the hospitals stays. In it, the annual costs directly generated by the patients (material, medication, medical fees, etc.) and the indirect costs which can not be exclusively imputed to the patients (administration, maintenance, etc.) are added. The sum of the costs is divided by all the hospital stays depending on the resources used. Thus, the cost of a hospital stay is calculated by documenting all the resources spent [Table 2].

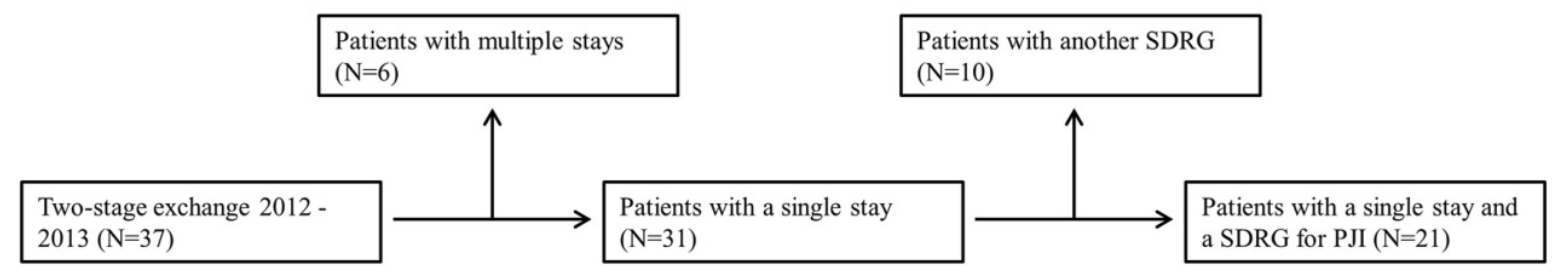

\section{Results}

\section{Patients}

37 prosthetic-joint infections were treated with a two-stage exchange in the Department of Septic Surgery at the University Hospital of Lausanne from 2012 to 2013. Six patients were excluded because they had multiple stays. 10 patients with another SDRG were also excluded. 21 patients were included [Table 3].

Table 2. Type of resources used.

\begin{tabular}{|c|c|c|}
\hline Surgical procedure & Cause of costs & Cost \\
\hline Material and implants & $\begin{array}{l}\text { Materiel and implants } \\
\text { used }\end{array}$ & Actual prices \\
\hline Operating theater & $\begin{array}{l}\text { Operating theater staff } \\
\text { time }\end{array}$ & $\begin{array}{l}\text { Duration of use } x \text { cost } \\
\text { per min }\end{array}$ \\
\hline Anesthesia & $\begin{array}{l}\text { Anesthesiologist and } \\
\text { nursing staff time }\end{array}$ & $\begin{array}{l}\text { Duration of anesthesia } x \\
\text { cost per min }\end{array}$ \\
\hline Blood & Blood transfusions & Actual prices \\
\hline Imagery & Radiological tests & Points $x$ point value \\
\hline \multicolumn{3}{|l|}{ Medical care } \\
\hline Medication & $\begin{array}{l}\text { Medication during } \\
\text { whole stay }\end{array}$ & Actual prices \\
\hline $\begin{array}{l}\text { Medical fees and } \\
\text { nursing }\end{array}$ & $\begin{array}{l}\text { Doctors and nursing } \\
\text { staff time }\end{array}$ & $\begin{array}{l}\text { Time required } x \text { cost per } \\
\text { min }\end{array}$ \\
\hline Hotel charges and food & Hotel charges and food & Daily fee \\
\hline Intensive care unit & $\begin{array}{l}\text { Treatment and nursing } \\
\text { staff time }\end{array}$ & $\begin{array}{l}\text { Time spent } x \text { cost per } \\
\text { min }\end{array}$ \\
\hline $\begin{array}{l}\text { Physiotherapy and } \\
\text { ergotherapy }\end{array}$ & $\begin{array}{l}\text { Physiotherapy and } \\
\text { ergotherapy }\end{array}$ & Points $x$ point value \\
\hline Laboratory & Laboratory tests & Points $x$ point value \\
\hline \multicolumn{3}{|l|}{ Administration } \\
\hline Management & $\begin{array}{l}\text { Reception, accounting } \\
\text { centers and archiving }\end{array}$ & Daily fee \\
\hline
\end{tabular}

Table 3. Patient's demographic characteristics.

\begin{tabular}{ll}
\hline Total patients 2012-2013 & $\mathbf{2 1}$ \\
\hline Hip prosthesis & 13 \\
Knee prosthesis & 8 \\
Interval time (weeks, median and range) & $3(1.6-6.3)$ \\
Length of stay (days, median and range & $38(27-70)$ \\
depending on the infecting agent) & \\
$\quad$ Staphylococcus aureus $(\mathrm{N}=3)$ & $42(31-57)$ \\
Coagulase-negative staphylococci $(\mathrm{N}=7)$ & $38(31-70)$ \\
Streptococcus spp. $(\mathrm{N}=4)$ & $31(28-63)$ \\
$\quad$ Gram-negative rods $(\mathrm{N}=1)$ & 50 \\
$\quad$ Cutibacterium acnes $(\mathrm{N}=2)$ & $39(36-42)$ \\
$\quad$ Culture-negative $\mathrm{PJI}(\mathrm{N}=4)$ & $35(27-39)$ \\
Age (median and range) & $67(56-88)$ \\
Male & 11 \\
Female & 10 \\
\hline
\end{tabular}

Figure 3. Flow of the patients selection. 
Number of points (costweight)

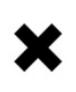

Price of a SDRG point (baserate)

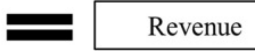

Figure 4. Remuneration computation.

\section{Revenues}

The remuneration for inliers from 2012 to 2013 ranged from 26'806 to 42'978 CHF ( 22'905-36'723 EUR, median 36'338 CHF, 31'049 EUR) depending on the SDRG, which is higher than similar studies.[13,15] Meanwhile, our hospital stays were sometimes up to twice as long than the average length for each SDRG (especially in infections with difficultto-treat microorganisms such as methicillin-resistant S. epidermidis) [Table 3 and Figure 5].

\section{Costs}

The median total cost per patient was $76^{\prime} 000$ CHF ( 65'000 EUR) (51'151 to 118'263; hip median $79^{\prime} 744$, knee median $66^{\prime} 708$ ), which is similar to costs found in other studies.[5-7] The overall costs allocation for the 21 patients is reported in Table 4 . More than two thirds of the costs came from the medical care and one third from the surgical procedure. The length of the hospital stay generated therefore the major part of the costs.

\section{Comparison between costs and revenues}

The revenues never covered all the costs, even with a short interval procedure $(<4$ weeks). The hospital lost a median of 35'000 CHF per patient ( $30^{\prime} 000$ EUR) (22'280 to 64'666) [Figure 6]. As the length of stay seemed to be the most relevant parameter to act on, a simple linear regression was carried out to investigate its relationship to the costs. The scatterplot showed that there was a linear relationship between the two, which was confirmed with the simple linear regression $(p$-value $=0.012)$. The slope coefficient was $-411 \mathrm{CHF}$ so the deficit increases by $411 \mathrm{CHF}(\sim 350$ EUR) for each extra day of hospital stay [Figure 7]. The $\mathrm{R}^{2}$ value was 0.332 so $33.2 \%$ of the increase in the deficit can be explained by the model containing only the length of stay.

Table 4. Costs allocation for the 21 patients.

\begin{tabular}{lll}
\hline Surgical procedure (32\%) & $\begin{array}{l}\text { Medical care } \\
\mathbf{( 6 7 \% )}\end{array}$ & $\begin{array}{l}\text { Administration } \\
\mathbf{( 1 \% )}\end{array}$ \\
\hline 13\% Material and implants & $34 \%$ Medication and nursing & 1\% Management \\
12\% Operating theater & 13\% Medical fees & \\
3\% Anesthesia & $8 \%$ Hotel charges and food & \\
3\% Blood & $5 \%$ Intensive care unit & \\
1\% Imagery & 5\% Physiotherapy and & \\
& ergotherapy & \\
& 2\% Laboratory & \\
\hline
\end{tabular}

\section{Discussion}

We observed that a main determinant of the costs was the length of stay. Several options could be considered to act on it. The innovative patient hotel concept, developed in Scandinavia in the 90s has proven to save money while maintaining high-quality care.[16-18] Already introduced in other DRG countries, the concept offers medical care in a private 3-stars hotel structure for patients who do not need to be on the acute inpatient ward but need to remain nearby the hospital for quick access to medical staff. This could be an interesting option between the explantation and the reimplantation in two-stage exchange to reduce the length of the hospital stay. It could also be possible to transfer temporally the patient to a rehabilitation hospital between the explantation and the reimplantation.

Another cost-saving potential would be to refer the patient back home with home caring and oral antibiotic therapy between the first and second stage of the surgical procedure. It has already been done in the German DRG system, on which the SwissDRG system is based.[13] With this solution, a new remuneration could be obtained with the second admission, in addition to decreasing the length of the hospital stay. According the SwissDRG

Figure 5. Average revenues per SDRG for 2012 and 2013 
system, the rehospitalization would have to take place after a period of 18 days in order to be considered as a new stay [Figure 8]. We compared the same costs and double revenues in a projection of the rehospitalization concept. The hospital would break even for our sample of patients (slope coefficient $=376 \mathrm{CHF}$, $p$-value $=0.05, \mathrm{R}^{2}$ value $\left.=0.214\right)$ [Figure 9] .

It is also crucial to have more specific SDRGs for prosthetic-joint infections. The three SDRGs applied for treating prosthetic-joint infections include uncomplicated cases (e.g. revision without infection) and complicated cases (e.g. revision for infection). This causes a decrease in the length of the SDRG and thus in its ensuring revenues.[19] The German DRG system suggest to stratify more by the principal diagnosis than the surgical procedure.[13]

Our study has several limitations. Our research focused on the two first years after the introduction of the SDRG system because only these two had a complete cost-analysis yet from our accounting centers. These two years also had a same base rate making the analysis more consistent. The cost-weights and base rates might have been adjusted since then but there is no specific SDRGs for prosthetic-joint infections today making our conclusion still topical.

Moreover, our research was not designed to take into account the patient's insurance type (i.e. basic, semi-private, private). The only difference is that patients with semi-private or private insurances $(\mathrm{N}=5 / 21)$ consume more resources in medical fees and hotel charges. Hence, the costs could be biased and overrated.

Our conclusion is limited due to the single- hospital perspective with a small sample size which undermine the external validity of our study. We had to exclude patients with multiple stays or with another SDRG because we didn't have the costs from other hospitals accounting centers or the remuneration was not the proper one for a prostheticjoint infection. There is a need of studies regarding the current economic impact in the healthcare system from a nationwide perspective. Additional research on prosthetic-joint infections is warranted using economic data, such as cost-effectiveness studies. It would be interesting to compare different interventions in treating prosthetic-joint infections to determine which one may best control infection and at the same time lower the economic burden.[20]

\section{Conclusion}

In summary, this study showed that the current SDRG system may not be specific enough for rewarding prosthetic-joint infections as revenues never covered all the costs. University hospitals treating more prosthetic-joint infections than other hospitals could be disadvantaged since the introduction of the SDRG system.[19] These results coincide with other similar studies.[5,13] Several options could be considered to act on the length of the hospital stay. It is also crucial that the SDRGs would be refined in order to reflect better the actual costs.

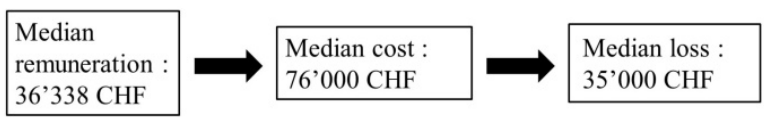

Figure 6. Comparison between costs and revenues.

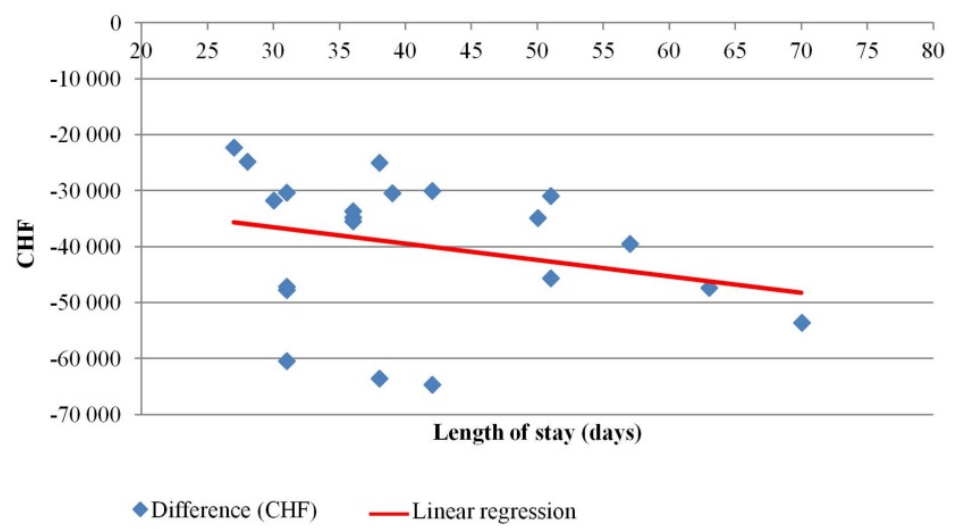

Figure 7. Difference between costs and revenues for each hospital stay.
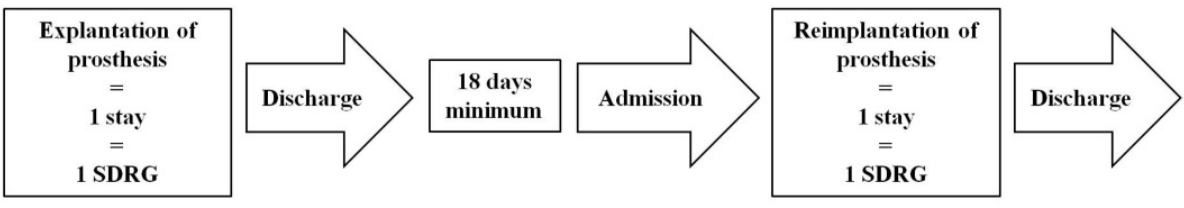

Figure 8. SDRG system for rehospitalization. 


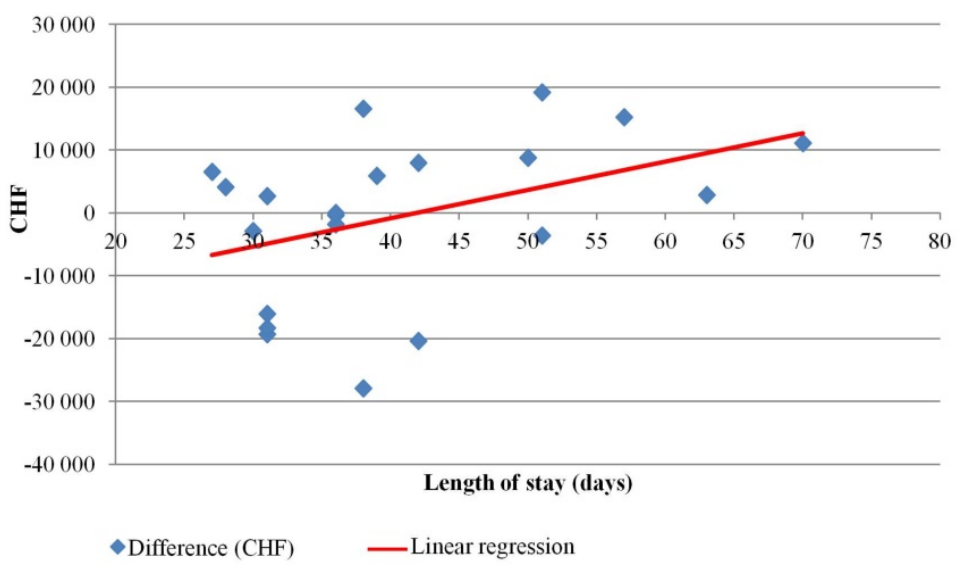

Figure 9. Difference between costs and double revenues.

\section{Competing Interests}

The authors have declared that no competing interest exists.

\section{References}

1. Borens $\mathrm{O}$, et al. Diagnostic et traitement des infections d'implants orthopédiques. Rev Med Suisse. 2009; 230: 2563-2568.

2. Zimmerli W, Trampuz A, Ochsner PE. Prosthetic-Joint Infections. N Engl J Med. 2004; 351: 1645-1654.

3. Borens $\mathrm{O}$, et al. Dix erreurs à ne pas commettre lors de la prise en charge d'une prothèse articulaire infectée en orthopédie. Rev Med Suisse. 2012; 367: $2452-2456$

4. Sculco TP. The economic impact of infected total joint arthroplasty. Instr Course Lect. 1993; 42: 349-351.

5. Haenle M, Skripitz C, Mittelmeier W, Skripitz R. Economic impact of infected total knee arthroplasty. ScientificWorldJournal. 2012; 2012: 196515.

6. Kurtz SM, Lau E, Schmier J, Ong KL, Zhao K, Parvizi J. Infection burden for hip and knee arthroplasty in the United States. J Arthroplasty. 2008; 23: 984-991.

7. Kurtz SM, Lau E, Watson H, Schmier JK, Parvizi J. Economic burden of periprosthetic joint infection in the United States. J Arthroplasty 2012; 27 (8 Suppl): $61-5$.

8. [Internet] SwissDRG. [15.12.15]. http://www.swissdrg.org.

9. [Internet] Stauber I, Angst F, Meier J, Lehmann S, Aeschlimann A, Michel B. Swiss Diagnosis Related Groups: A prospective study in rehabilitation comparing outcome before and after its introduction into acute health care. Swiss Med Wkly. 2014 [15.12.15]. http://doi.emh.ch/smw.2014.14004

10. Busse R, Geissler A, Aaviksoo A, Cots F, Häkkinen U, Kobel C, et al. Diagnosis related groups in Europe: moving towards transparency, efficiency, and quality in hospitals? BMJ. 2013; 346: f3197.

11. [Internet] Manuel de codage et circulaires 2015 [15.12.15] http://www.bfs.admin.ch/bfs/portal/fr/index/infothek/nomenklaturen/bl ank/blank/codage/04/04_05.html\#parsys_20081.

12. [Internet] Tarmedsuisse. [15.12.15]. http://www.tarmedsuisse.ch.

13. Lieb E, Hanstein T, Schuerings M, Trampuz A, Perka C. Reduction of Treatment Duration in Periprosthetic Infection with a Fast-Track Concept Is Economically Not Feasible. Z Orthopadie Unfallchirurgie. 2015.

14. [Internet] REKOLE $®$ manuel, 4ème édition. 2013 [15.12.15]. http://www.hplus.ch/fr/prestations/gestion/comptabilite_des_hopitaux/r ekoler_manuel.

15. Hellmann M, Mehta SD, Bishai DM, Mears SC, Zenilman JM. The Estimated Magnitude and Direct Hospital Costs of Prosthetic Joint Infections in the United States, 1997 to 2004. J Arthroplasty. 2010; 25: 766-771.

16. [Internet] Un hôtel trois étoiles logera les patients du CHUV. 24heures.ch. 2015 [15.12.15].

http://www.24heures.ch/vaud-regions/hotel-trois-etoiles-logera-patients-ch uv/story/16983531.

17. [Internet] Could state-funded patient hotels be the future? The Guardian. 2013 [15.12.15].

http://www.theguardian.com/healthcare-network/2013/mar/26/state-fund ed-patient-hotels-future.

18. [Internet] Avec son futur hôtel des patients, le CHUV s'inspire de la $\begin{array}{lll}\text { Scandinavie. } & \text { Letemps.ch. } & 2015 \\ \text { [15.12.15]. }\end{array}$ http://www.letemps.ch/suisse/2015/06/23/futur-hotel-patients-chuv-s-ins pire-scandinavie.
19. [Internet] Bulletin des médecins suisses. 2013 [15.12.15]. http://www.bullmed.ch/archives/editions.html?tx eps toc $\% 5$ Bissue $\% 5 \mathrm{D}=1$ 05\&tx_eps_toc $\% 5$ Baction $\% 5 \mathrm{D}=$ issue.

20. [Internet] Vaquero D, Fairen M, Torres A, Menzie AM, et al. Treatment of Periprosthetic Infections: An Economic Analysis. Sci World J. 2013. [15.12.15]. http://www.hindawi.com/journals/tswj/2013/821650/abs/. 